\title{
Bone Cancer Mortality in Inner Mongolia from 2008 to 2012
}

\author{
Wenfang Guo, Wenli Hao, Maolin Du, Zhuang Su, Yuelin Hu, Yuan Xia, Xiong Su, Juan Sun* \\ Inner Mongolia Medical University, Hohhot, China \\ Email: ${ }^{*}$ cnsunjuan@aliyun.com
}

Received 20 January 2015; accepted 12 February 2015; published 17 February 2015

Copyright (C) 2015 by authors and Scientific Research Publishing Inc.

This work is licensed under the Creative Commons Attribution International License (CC BY). http://creativecommons.org/licenses/by/4.0/

\section{(c) (i) Open Access}

\begin{abstract}
Objective: The aim of our study was to assess bone cancer mortality and the related social factors in Inner Mongolia in China. Methods: We obtained data from the Centers for Disease Control in Inner Mongolia from five monitoring points of the Death Registry System in Inner Mongolia from 2008 to 2012. We calculated the crude mortality rate for bone cancer. The $\chi^{2}$ test was used to examine differences in bone cancer mortality rates between sexes and years. Unconditional logistic regressions were applied to analyze the effect of socio-demographic characteristics by sex. Results: Between 2008 and 2012, the crude mortality rate of bone cancer was $1.12 / 100000$ (95\% confidence interval $=1.02-1.21$ ). The bone cancer mortality was 2.24 in men and 1.25 in women, resulting in a male-female ratio of 1.8. No between-year difference in the mortality rate was observed between 2008 and 2012 (men: $\chi^{2}=4.65, P=0.325$; women: $\chi^{2}=2.21, P=0.698$ ). In general, mortality increased with increasing age. People with a lower education level exhibited an increased risk of bone cancer among both men and women. Jobs involving extensive manual labor decreased the likelihood of bone cancer mortality, and the odds ratio was higher for men than women ( 0.6 vs. 0.45$)$. Unmarried people had a higher risk for bone cancer than married people. Conclusion: The mortality rate of bone cancer was not significantly different between men and women from 2008 to 2012 . The risk of bone cancer increased with age among both sexes. Unmarried people and those with a low education status had an elevated risk of bone cancer, whereas employment in a field involving extensive manual labor appeared to be a protective factor against bone cancer.
\end{abstract}

\section{Keywords}

Bone Cancer, Mortality, Cause of Death

\footnotetext{
${ }^{*}$ Corresponding author.
}

How to cite this paper: Guo, W.F., Hao, W.L., Du, M.L., Su, Z., Hu, Y.L., Xia, Y., Su, X. and Sun, J. (2015) Bone Cancer Mortality in Inner Mongolia from 2008 to 2012. Open Journal of Epidemiology, 5, 59-64. 


\section{Introduction}

Bone cancer is rare, comprising less than $1 \%$ of all cancers; however, it is the seventh most common type of cancer in adolescents, representing 5\% of all cancers in those aged 0 - 19 years [1]. Because the incidence of bone cancer is clearly age-dependent, an analysis of its incidence by age groups would be more meaningful [2] [3]. Bone cancer imposes the risk of permanent restrictions in mobility, reduced function or even the loss of a limb, and possible physical disfigurement [4]. Reported or proposed risk factors for bone cancer include age, male sex, education, occupation, marital status, and area of residence [4] [5]. There is marked geographic variation observed in the prevalence of Paget's disease, with a high prevalence noted in the UK, Australia, and North America and a lower prevalence observed in Asia and the Middle East [6] [7].

Hence, our study was designed to assess bone cancer mortality rates and the associated social factors in the Inner Mongolia region of China. The data covered a large population and reflected the most recent status in Inner Mongolia.

\section{Materials and Methods}

\subsection{Data Source}

We obtained data covering the period 2008-2012 based on International Classification of Diseases, Tenth Revision (ICD-10) codes from the Death Registry System (DRS) maintained by the Inner Mongolia Centers for Disease Control and Prevention (CDC) [8]. The system collects data from five monitoring points of the DRS in Inner Mongolia, namely Kailu County, Bairin Youqi, Sonid Youqi, Muslims District, and Linhe District [9] [10].

The ICD-10 codes for bone cancer used in this study were as follows: C40, malignant neoplasm of bone and articular cartilage of limbs; and C41, malignant neoplasm of bone and articular cartilage of other and unspecified sites. The annual midyear population figures between 2008 and 2012 were obtained from the CDC of Inner Mongolia to calculate age-specific mortality rates and the annual mortality rate per 100,000 people. Occupational status, marital status, and location of residence (urban/rural) were chosen as the indicators to assess the demographic characteristics of bone cancer mortality.

\subsection{Statistical Analysis}

The bone cancer mortality rate (per 100,000 people) and corresponding 95\% confidence interval (CI) were calculated. A line graph was drawn to illustrate the age-specific mortality rate, and a histogram was used to illustrate bone cancer mortality rates from 2008 to 2012 by sex. The $\chi^{2}$ test was used to examine differences between sexes and years in bone cancer mortality rates. Unconditional logistic regressions were applied to analyze the effect of socio-demographic characteristics by sex. Odds ratios (ORs) and corresponding 95\% CIs were calculated. The variables selected from the DRS included age, marital status, occupation status, education level, and area of residence. Marital status was divided into married and unmarried, with married taken as the reference group. Occupation status was divided into light and extensive manual labor, with light manual labor taken as the reference group. Education level was divided into illiterate and primary school education and middle school or higher, with middle school or higher taken as the reference group. Area of residence was divided into urban and rural, with urban taken as the reference group.

Microsoft Excel and SPSS 13.0 statistical software were used for data management and analysis. $\mathrm{P} \leq 0.05$ was considered statistically significant throughout this study.

\section{Results}

During the period 2008-2012, the crude bone cancer mortality rate was 1.12/100000 (95\% CI = $1.02-1.21)$. The mortality rate by sex was 2.24 in men and 1.25 in women, resulting in a male-female ratio of 1.8 .

Figure 1 shows that by sex, the crude bone cancer mortality rate was higher among men than among women between 2008 and 2012, although the male-female ratio decreased over time. The ratio of the bone cancer mortality rate between the sexes was 2.9 in 2008, versus 1.4 in 2012. Meanwhile, no significant between-year difference in the mortality rate was observed between 2008 and 2012 (men: $\chi^{2}=4.65, \mathrm{P}=0.325$; women: $\chi^{2}=2.21$, $\mathrm{P}=0.698$ ).

Figure 2 presents the age-related mortality rates for bone cancer by sex at five monitoring points from 2008 


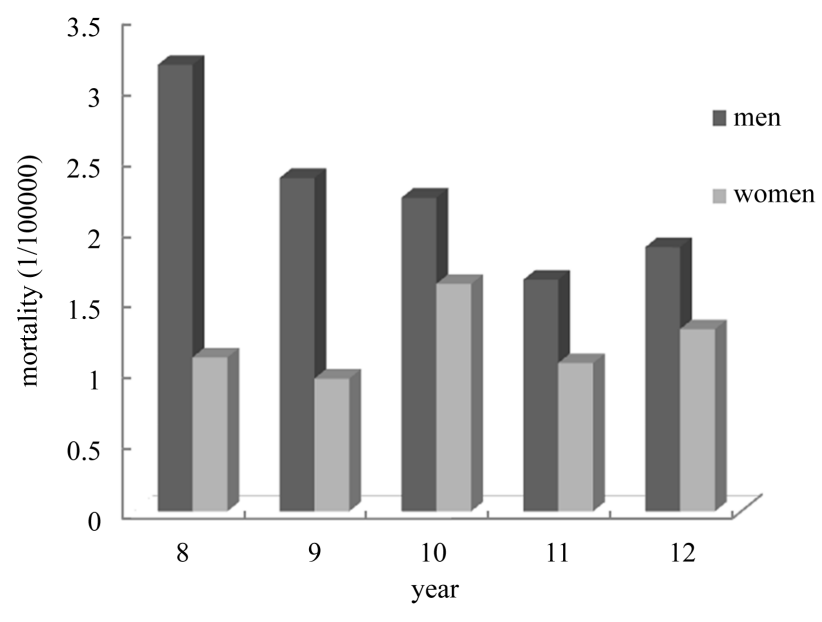

Figure 1. Crude bone cancer mortality rates at five monitoring points in Inner Mongolia between 2008 and 2012 for men and women.

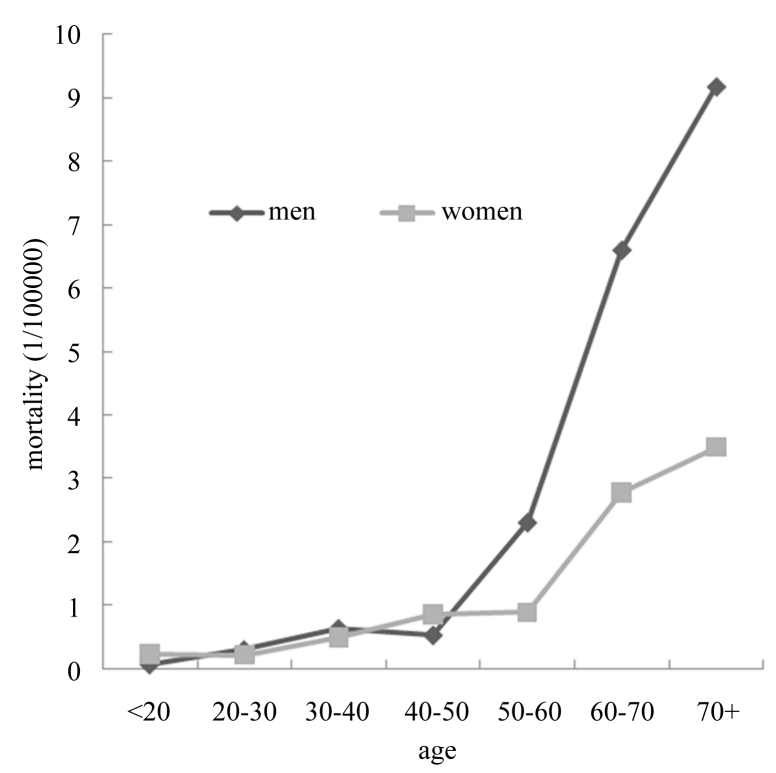

Figure 2. Age-related mortality rates for bone cancer by sex at five monitoring points between 2008 and 2012 for men and women.

to 2012. In general, mortality increased with increasing age. There was a sharp upward trend for men and women aged 50 years old and older. Meanwhile, the mortality rate peaked in women aged 40 - 50 years, who exhibited a higher rate than their male counterparts.

Table 1 shows the results of multivariate analyses of socio-demographic characteristics and the risk of bone cancer for men and women separately. Men and women with a lower education level exhibited an increased risk of bone cancer. Workers in fields involving extensive manual labor displayed a lower risk of bone cancer mortality, although the OR was higher for men than women (0.6 vs. 0.45). Unmarried people had a higher risk of bone cancer than married people. There was no statistically significant relationship between living in a rural or urban area and the risk of bone cancer.

\section{Discussion}

The bone cancer mortality rate in Inner Mongolia was higher than that in Western countries [2] [11] but lower 
Table 1. Logistic regression analysis of socio-demographic characteristics for bone cancer mortality according to sex.

\begin{tabular}{|c|c|c|c|c|c|c|}
\hline \multirow[b]{2}{*}{ Characteristic } & \multicolumn{3}{|c|}{ Men } & \multicolumn{3}{|c|}{ Women } \\
\hline & $\mathbf{P}$ & OR & $95 \% \mathrm{CI}$ & $\mathbf{P}$ & OR & $95 \%$ CI \\
\hline \multicolumn{7}{|l|}{ Marital status } \\
\hline Unmarried & 0.016 & 1.58 & $1.18-5.18$ & 0.046 & 2.67 & $1.02-7.03$ \\
\hline Married & & 1.00 & & & 1.00 & \\
\hline \multicolumn{7}{|l|}{ Occupation } \\
\hline Extensive manual labor & $<0.001$ & 0.6 & $0.54-0.89$ & 0.032 & 0.45 & $0.22-0.94$ \\
\hline Light manual labor & & 1.00 & & & 1.00 & \\
\hline \multicolumn{7}{|l|}{ Education level } \\
\hline Illiterate and primary school & $<0.001$ & 3.5 & $3.20-3.83$ & $<0.001$ & 3.87 & $3.28-4.58$ \\
\hline Middle school and higher & & 1.00 & & & 1.00 & \\
\hline Area of residence & 0.22 & & & 0.57 & & \\
\hline \multicolumn{7}{|l|}{ Urban } \\
\hline Rural & & & & & & \\
\hline
\end{tabular}

Abbreviations: OR—odds ratio; CI—confidence interval.

than that in some Asian countries [3] [12]. In our study, the bone cancer mortality rate was consistently higher for men than for women from 2008 to 2012 (2.23 vs. 1.79). However, the rate was lower than the world average (2.27 - 2.39 and 3.3 - 4.6 per million individuals for men and women, respectively) [3].

This study found that the risk of bone cancer was greater in women than in men younger than 40 - 50 years, whereas in men and women older than 50 years, a sharp upward trend in bone cancer risk was observed. Some previous findings supported our result [2] [3]. This suggests that the etiology of bone cancer may be hormonally driven, leading to differences in skeletal growth between men and women, especially among young people [13]. Older people have a higher risk for bone cancer death. Vitamin D deficiency is recognized as pandemic, and the elderly may be particularly affected [14]. It is theoretically possible that vitamin D deficiency could contribute to the risk of bone cancer, as vitamin $\mathrm{D}$ is required for bone development and vitamin $\mathrm{D}$ deficiency has been associated with bone and other cancers [15]. Different environmental and/or genetic risk factors could also be involved in the development of bone cancer in the elderly [3].

Bone cancer rates were highest among the lower educated segment of the population. This finding is consistent with most existing studies [16] [17]. People with a lower education level experience a higher burden of cancer [17]. By contrast, a high level of education may be linked to increased knowledge of health or greater physical activity. Physical activity may help to maintain bone health [18]. Our result also illustrated that people employed in fields involving extensive manual labor had a lower risk of bone cancer mortality. Physical activity among people employed in fields involving extensive manual labor may result in greater bone density [19].

The findings of our study illustrated that unmarried people had a higher risk of bone cancer than married people. Reports on health and mortality by marital status have consistently identified that unmarried individuals generally report poorer health, and they have greater risks of cancer mortality than their married counterparts. A study reported that unmarried patients are at significantly higher risk of presentation with metastatic cancer [20]. Caring and helpful spousal behaviors contribute to physical health [21].

\section{Conclusion}

In conclusion, we reported the characteristics of bone cancer in Inner Mongolia from 2008 to 2012. The mortality rate of bone cancer was not significantly difference between men and women during this period. The risk of bone cancer increased with increasing age in both men and women. Unmarried people and those with a low education status had a greater risk of bone cancer. Meanwhile, employment in a field involving extensive ma- 
nual labor appeared protective against bone cancer. Further studies are needed to assess more recent trends in bone cancer mortality.

\section{Acknowledgements}

This work was supported by Inner Mongolia Autonomous Region Colleges and Universities of Science and Technology Research Projects (No. NJZY13415), the Inner Mongolia Medical University Technology million project (No. NY2011BW006), and the Natural Science Foundation of Inner Mongolia in China (2013MS1124).

\section{References}

[1] Li, J., Thompson, T.D., Miller, J.W., Pollack, L.A. and Stewart, S.L. (2008) Cancer Incidence among Children and Adolescents in the United States, 2001-2003. Pediatrics, 121, e1470-e1477. http://dx.doi.org/10.1542/peds.2007-2964

[2] Mirabello, L., Troisi, R.J. and Savage, S.A. (2009) Osteosarcoma Incidence and Survival Rates from 1973 to 2004 : Data from the Surveillance, Epidemiology, and End Results Program. Cancer, 115, 1531-1543. http://dx.doi.org/10.1002/cncr.24121

[3] Mirabello, L., Troisi, R.J. and Savage, S.A. (2009) International Osteosarcoma Incidence Patterns in Children and Adolescents, Middle Ages and Elderly Persons. International Journal of Cancer, 125, 229-234. http://dx.doi.org/10.1002/ijc.24320

[4] Felder-Puig, R., Formann, A.K., Mildner, A., Bretschneider, W., Bucher, B., Windhager, R., et al. (1998) Quality of Life and Psychosocial Adjustment of Young Patients after Treatment of Bone Cancer. Cancer, 83, 69-75. http://dx.doi.org/10.1002/(SICI)1097-0142(19980701)83:1<69::AID-CNCR10>3.0.CO;2-A

[5] Troisi, R., Stephansson, O., Jacobsen, J., Tretli, S., Sørensen, H.T., Gissler, M., et al. (2014) Perinatal Characteristics and Bone Cancer Risk in offspring-A Scandinavian Population-Based Study. Acta Oncologica, 53, 830-838. http://dx.doi.org/10.3109/0284186X.2013.862594

[6] Colina, M., La Corte, R., De Leonardis, F. and Trotta, F. (2008) Paget’s Disease of Bone: A Review. Rheumatology International, 28, 1069-1075. http://dx.doi.org/10.1007/s00296-008-0640-6

[7] Cooper, C., Harvey, N.C., Dennison, E.M. and van Staa, T.P. (2007) Update on the Epidemiology of Paget's Disease of Bone. Journal of Bone and Mineral Research, 21, P3-P8. http://dx.doi.org/10.1359/jbmr.06s201

[8] Li, Q, Xin, K., Liu, R., Li, Y., Li, W., Su, X., et al. (2014) Breast Cancer in Inner Mongolia 2009-2011. Open Journal of Epidemiology, 4, 63-68. http://dx.doi.org/10.4236/ojepi.2014.42011

[9] Hu, Y., Li, Y., Wang, W., Qian, Y., Hui, C., Xin, K., et al. (2014) The Characteristics of Breast Cancer Mortality in Inner Mongolia between 2008 and 2010. Open Journal of Epidemiology, 4, 135-140. http://dx.doi.org/10.4236/ojepi.2014.43019

[10] Xin, K.P., Du, M.L., Liu, Z.Y., Wang, W.R., Qian, Y.G., Liu, L., et al. (2014) Colorectal Cancer Mortality in Inner Mongolia between 2008 and 2012. World Journal of Gastroenterology, 20, 8209-8214. http://dx.doi.org/10.3748/wjg.v20.i25.8209

[11] Guo, W., Xu, W., Huvos, A.G., Healey, J.H. and Feng, C. (1999) Comparative Frequency of Bone Sarcomas among Different Racial Groups. Chinese Medical Journal, 112, 1101-1104.

[12] Hung, G.Y., Horng, J.L., Yen, H.J., Yen, C.C., Chen, W.M., Chen, P.C., et al. (2014) Incidence Patterns of Primary Bone Cancer in Taiwan (2003-2010): A Population-Based Study. Annals of Surgical Oncology, 21, 2490-2498. http://dx.doi.org/10.1245/s10434-014-3697-3

[13] dos Santos Silva, I. and Swerdlow, A.J. (1993) Sex Differences in the Risks of Hormone-Dependent Cancers. American Journal of Epidemiology, 138, 10-28.

[14] Holick, M.F., Matsuoka, L.Y. and Wortsman, J. (1989) Age, Vitamin D, and Solar Ultraviolet. Lancet, 2, $1104-1105$. http://dx.doi.org/10.1016/S0140-6736(89)91124-0

[15] Garland, C.F., Garland, F.C., Gorham, E.D., Lipkin, M., Newmark, H., Mohr, S.B., et al. (2006) The Role of Vitamin D in Cancer Prevention. American Journal of Public Health, 96, 252-261. http://dx.doi.org/10.2105/AJPH.2004.045260

[16] Gallo. V., Mackenbach, J.P., Ezzati, M., Menvielle, G., Kunst, A.E., Rohrmann, S., et al. (2012) Social Inequalities and Mortality in Europe-Results from a Large Multi-National Cohort. PLOS ONE, 7, e39013. http://dx.doi.org/10.1371/journal.pone.0039013

[17] Puigpinós, R., Borrell, C., Antunes, J.L., Azlor, E., Pasarín, M.I., Serral, G., et al. (2009) Trends in Socioeconomic Inequalities in Cancer Mortality in Barcelona: 1992-2003. BMC Public Health, 9, 35. http://dx.doi.org/10.1186/1471-2458-9-35 
[18] Gremeaux, V., Gayda, M., Lepers, R., Sosner, P., Juneau, M. and Nigam, A. (2012) Exercise and Longevity. Maturitas, 73, 312-317. http://dx.doi.org/10.1016/j.maturitas.2012.09.012

[19] Elliot, J.R., Gilchrist, N.L. and Wells, J.E. (1996) The Effect of Socioeconomic Status on Bone Density in a Male Caucasian Population. Bone, 18, 371-373. http://dx.doi.org/10.1016/8756-3282(96)00006-3

[20] Aizer, A.A., Chen, M.H., McCarthy, E.P., Mendu, M.L., Koo, S., Wilhite, T.J., et al. (2013) Marital Status and Survival in Patients with Cancer. Journal of Clinical Oncology, 31, 3869-3876. http://dx.doi.org/10.1200/JCO.2013.49.6489

[21] Bookwala, J. (2005) The Role of Marital Quality in Physical Health during the Mature Years. Journal of Aging and Health, 17, 85-104. http://dx.doi.org/10.1177/0898264304272794 
Scientific Research Publishing (SCIRP) is one of the largest Open Access journal publishers. It is currently publishing more than 200 open access, online, peer-reviewed journals covering a wide range of academic disciplines. SCIRP serves the worldwide academic communities and contributes to the progress and application of science with its publication.

Other selected journals from SCIRP are listed as below. Submit your manuscript to us via either submit@scirp.org or Online Submission Portal.
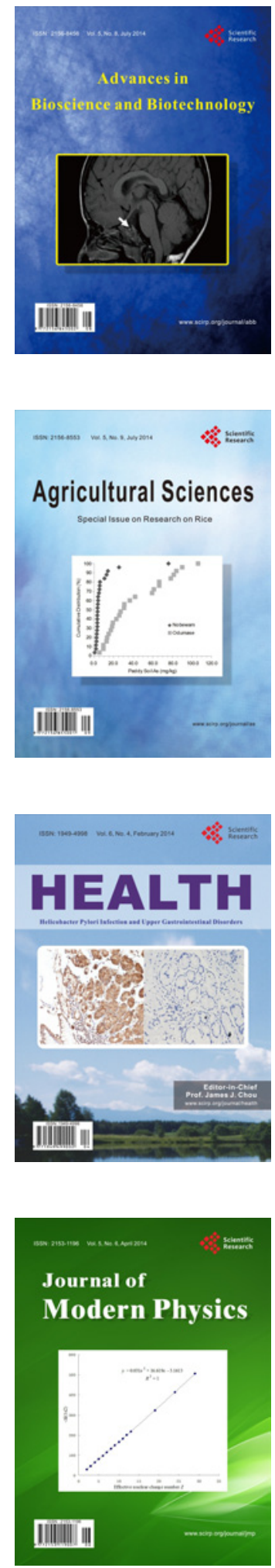
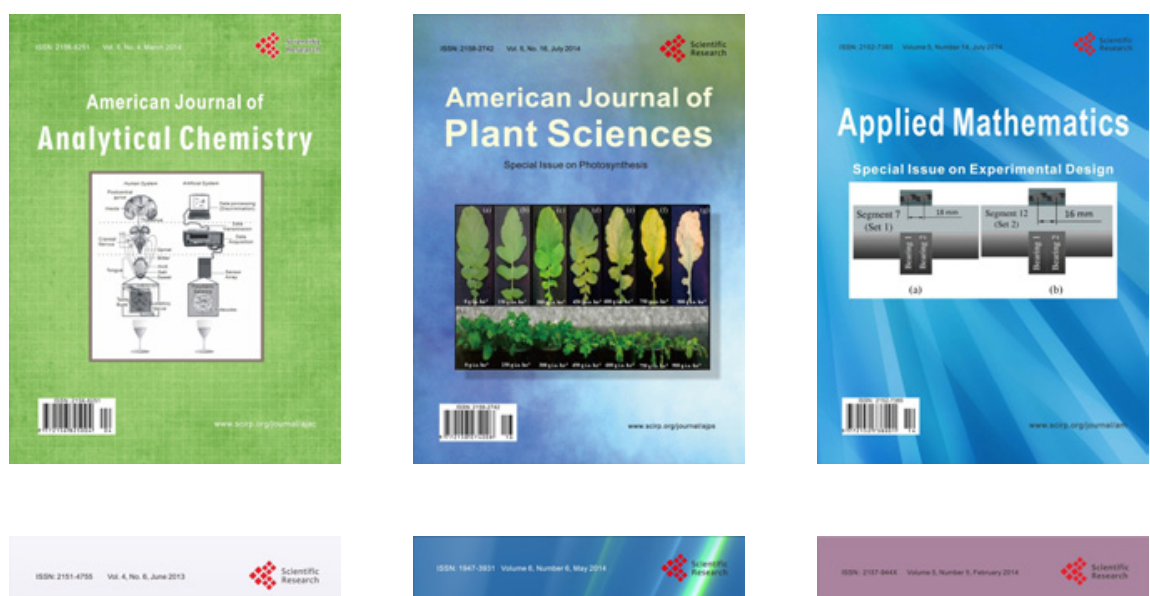

Creative Education
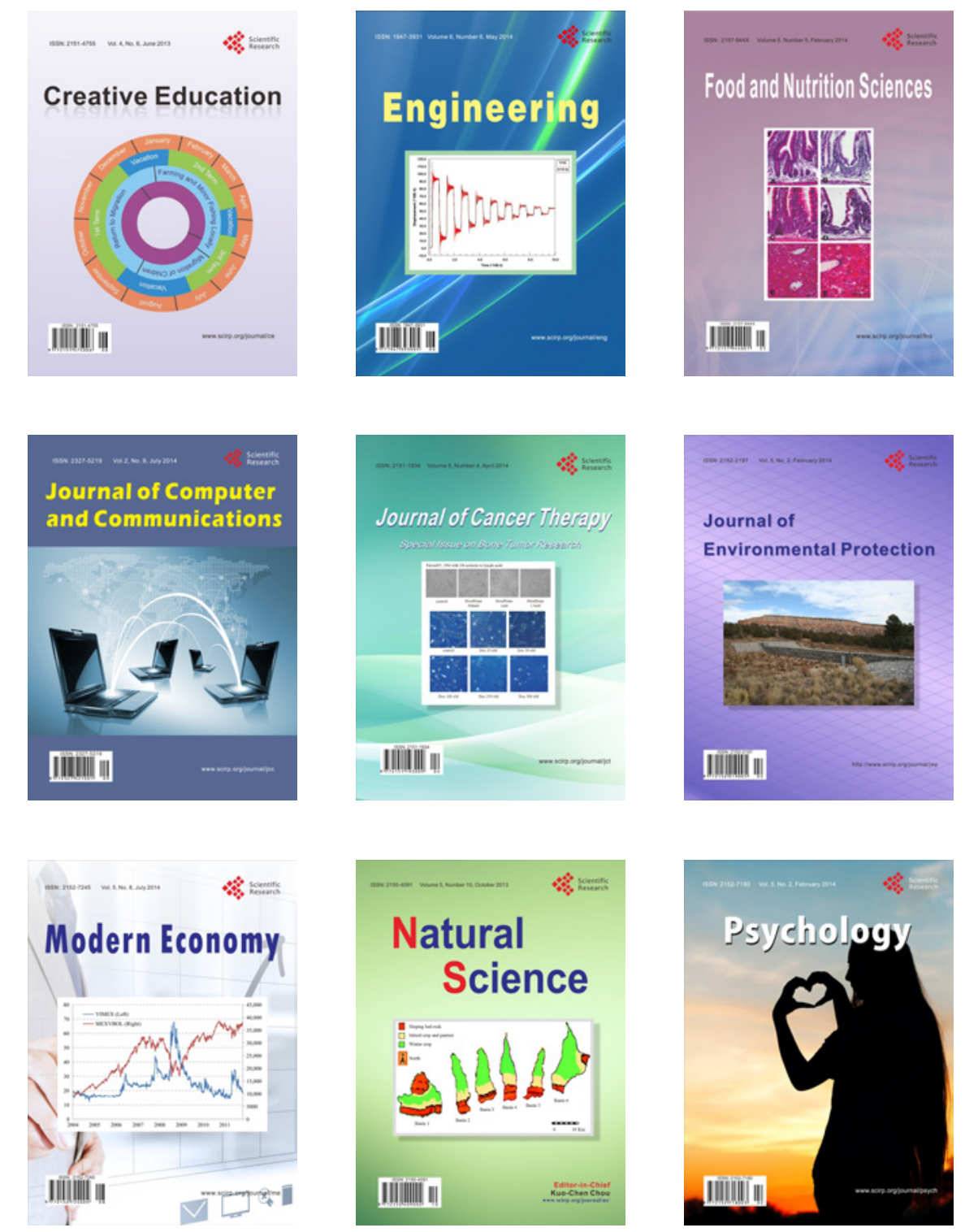